\title{
Theory of reasoned action and theory of planned behavior-based dietary interventions in adolescents and young adults: a systematic review
}

This article was published in the following Dove Press journal:

Adolescent Health, Medicine and Therapeutics

6 June 2014

Number of times this article has been viewed

\author{
Christine L Hackman \\ Adam P Knowlden \\ Department of Health Science, \\ The University of Alabama, \\ Tuscaloosa, AL, USA
}

Correspondence: Christine Hackman Department of Health Science, The University of Alabama, Tuscaloosa Alabama, USA 207 Adams Hall Box 870I58 Tuscaloosa, AL 35487, USA

Tel + I 20534843 I3

Email clhackman@crimson.ua.edu
Background: Childhood obesity has reached epidemic proportions in many nations around the world. The theory of planned behavior (TPB) and the theory of reasoned action (TRA) have been used to successfully plan and evaluate numerous interventions for many different behaviors. The aim of this study was to systematically review and synthesize TPB and TRA-based dietary behavior interventions targeting adolescents and young adults.

Methods: The following databases were systematically searched to find articles for this review: Academic Search Premier; Cumulative Index to Nursing and Allied Health (CINAHL); Education Resources Information Center (ERIC); Health Source: Nursing/Academic Edition; Cochrane Central Register of Controlled Trials (CENTRAL); and MEDLINE. Inclusion criteria for articles were: 1) primary or secondary interventions, 2) with any quantitative design, 3) published in the English language, 4) between January 2003 and March 2014, 5) that targeted adolescents or young adults, 6) which included dietary change behavior as the outcome, and 7) utilized TPB or TRA.

Results: Of the eleven intervention studies evaluated, nine resulted in dietary behavior change that was attributed to the treatment. Additionally, all but one study found there to be a change in at least one construct of TRA or TPB, while one study did not measure constructs. All of the studies utilized some type of quantitative design, with two employing quasi-experimental, and eight employing randomized control trial design. Among the studies, four utilized technology including emails, social media posts, information on school websites, web-based activities, audio messages in classrooms, interactive DVDs, and health-related websites. Two studies incorporated goal setting and four employed persuasive communication.

Conclusion: Interventions directed toward changing dietary behaviors in adolescents should aim to incorporate multi-faceted, theory-based approaches. Future studies should consider utilizing randomized control trial design and operationalize variables. More research is needed to identify the optimal TPB and TRA modalities to modify dietary behaviors.

Keywords: youth, nutrition behavior, theory of planned behavior, theory of reasoned action

\section{Introduction}

According to the World Health Organization, ${ }^{1}$ obesity is a chronic disease that affects people of all ages in every region of the world. Obesity is a major public health concern; excess adipose tissue is associated with a myriad of health problems and is attributable to many common causes of mortality. ${ }^{2,3}$ Among youth, obesity has reached epidemic proportions around the world, ${ }^{1}$ and is a significant contributor to adult obesity. ${ }^{4}$ In the United States alone, at least one-third of children and adolescents are overweight or obese..$^{5}$ During the last 30 years, childhood obesity has more than doubled and adolescent obesity has increased threefold. ${ }^{5}$ Although the highest rates of obesity are generally 
observed in industrialized nations such as the United States, developing nations alike are experiencing a sharp increase in obesity rates as their economies grow and thrive.

According to the energy balance model $^{6}$ of obesity, when more calories are consumed than expended, the result is a positive energy balance that, if sustained, results in an increase in adipose tissue. Although this equation seems simple, many intrapersonal, genetic, and environmental factors contribute to this energy balance. ${ }^{7}$ Poor dietary behaviors are associated with obesity, while performing behaviors such as consuming more fruits and vegetables (FV), although not directly related to prevention of obesity, are theorized to reduce the intake of poor quality, energy dense foods, thus reducing a positive energy balance. ${ }^{8}$

Often, health behavior theories are employed to provide guidance in designing, implementing, and evaluating interventions for prevention of obesity. Health behavior research has revealed that the most effective dietary interventions are those that are theory driven and behaviorally focused. ${ }^{9}$ The theory of planned behavior (TPB) is a commonly utilized intrapersonal theory that is used to predict behavioral intention and behavior. ${ }^{10}$ TPB is an extension of the theory of reasoned action (TRA), ${ }^{11}$ which assumes that behaviors examined in this model are under total voluntary control. To account for behaviors that were not necessarily under volitional control, perceived behavioral control (PBC) was added to TRA. ${ }^{10}$ TPB incorporates three main constructs that contribute to behavioral intention, which is considered the strongest predictor of behavior. ${ }^{12}$

Attitude towards a behavior refers to whether an individual holds a positive or negative view of the health behavior under examination. Attitude is comprised of beliefs, knowledge and values, and a determination of whether the outcomes of a behavior are positive or negative, ${ }^{10,11}$ and attitude tends to be a moderate predictor of behavioral intention. ${ }^{12}$ Subjective norms is the perceived social pressure to perform a behavior. It involves an individual's beliefs about whether significantothers would approve or disapprove of a behavior, as well as an individual's motivation to comply with significant-others' expectations. ${ }^{11}$ Although influential in many behaviors, subjective norms is generally a poor predictor of behavioral control possibly due to the lack of sufficient measurement. ${ }^{12}$ $\mathrm{PBC}$ refers to the amount of control an individual feels she or he has over performing a behavior; it has been considered to be a moderate predictor of behavioral intention that directly predicts behavior. ${ }^{12}$ However, some behaviors are out of the control of the individual, which is why actual behavioral control is commonly included in this model. Actual behavioral control directly affects behavior and is generally considered to exert influence between behavioral intention and behavior within the TPB. For example, if an individual has a favorable attitude towards consuming FV, perceives FV consumption to be positively viewed by significant others, and feels as if he or she is in control of FV consumption, that individual will likely intend to consume FV. However, if the individual does not have access to FV due to a food desert (an area in which fresh fruits and vegetables and other foods that comprise a healthy diet are not available), he or she are said to not have actual behavioral control over FV consumption.

Based on a TPB meta-analysis by Armitage and Conner, ${ }^{12}$ attitudes, subjective norms, and PBC accounted for 39\% of the variance in intention, and intention accounted for $25 \%$ of variance, when examining a wide range of health behaviors. Furthermore, PCB alone accounted for an additional 2\% of variance in behavior beyond the effect of intention. The TPB has been used to successfully plan and evaluate numerous interventions for many different behaviors, including sexual behavior, smoking, and exercise, among others. ${ }^{13}$ Recent research has utilized the TPB to predict dietary behavioral intention and behavior, but few interventions have been developed based off the TPB. Even fewer TPB-based dietary behavior interventions have been developed for adolescent or young adult populations.

Dietary behaviors in the adolescent and young adult populations are of great concern. Most young people do not consume a healthy diet consistent with current food intake recommendations. ${ }^{14}$ Additionally, during adolescence and young adulthood, individuals exercise increasing control over their everyday life, including their diet. Theory-driven, dietary behavioral interventions for adolescents and young adults are relatively sparse, and have yet to be systematically reviewed for effectiveness and overall recommendations. Subsequently, the aim of this inquiry was to systematically review and synthesize TPB and TRA-based dietary behavior interventions for adolescents and young adults.

\section{Methods}

Interventions with the following inclusion criteria were contained within in this review: 1) primary and secondary prevention and studies; 2) with any quantitative design; $3)$ published in an academic journal; 4) in the English language; 5) between 2003 and 2013; 6) that were interventions; 7) that targeted adolescents or young adults; 7) which included dietary change behavior as the outcome; and 8) utilized TPB or TRA. Exclusion criteria discarded interventions that: 1) did not use a quantitative design, 2) did not included dietary 
behavior change as the outcome, and 3) were not included in a search indexed in at least one of the following databases: Academic Search Premier, Cumulative Index to Nursing and Allied Health (CINAHL), Education Resources Information Center (ERIC), Health Source: Nursing/Academic Edition, Cochrane Central Register of Controlled Trials (CENTRAL); and MEDLINE.

Utilizing the inclusion and exclusion criteria, the data extraction process spanned four phases. During phase one, Boolean search terms of "Theory of Planned Behaviour AND Food AND Intervention" were applied to pool the first round of articles from Academic Search Premier $(n=76)$, CINAHL $(n=10)$, ERIC $(n=8)$, and Health Source: Nursing/Academic Edition $(n=27)$, resulting in a total of 121 articles. Phase two included removing articles that were duplicates $(n=6)$, review articles $(n=4)$, manuscripts which did not include an intervention $(n=45)$, and those that were irrelevant to the purpose statement $(n=57)$, for a total of 18 articles. During phase three, the remaining articles were reviewed by two independent researchers. Both researchers concluded that several of the articles did not target the population of interest $(n=6)$, and that some articles did not employ TPB $(n=2)$. To reduce the chance of missing articles that fit the inclusion criteria, phase four included conducting a descendent search of all articles extracted during phase two $(n=1)$. After phases one to four, a total of 11 articles fit the inclusion criteria, as illustrated in Figure 1.

\section{Results}

Details of each study are outlined in Table 1, including: target population, age of participants enrolled, TPB constructs employed, intervention groups, intervention and duration and evaluation timeline, intervention activities, and intervention outcomes. Interventions are arranged alphabetically by last name of the first author.

Anderson et $\mathrm{al}^{15}$ developed and assessed a school-based nutritional 9-month program that aimed to increase FV consumption in 6-7 and 10-11 year olds in elementary schools

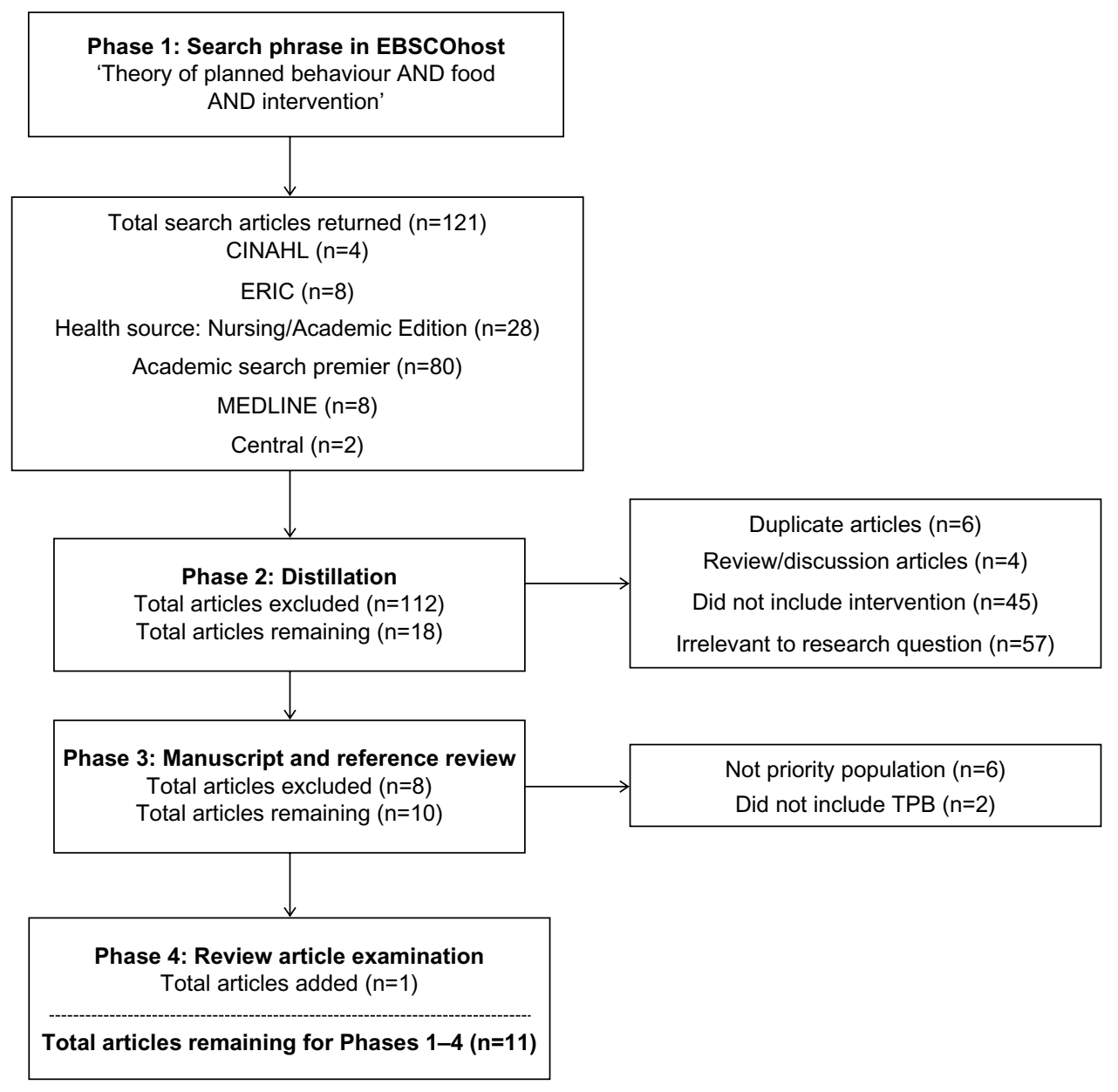

Figure I Flow chart portraying the four phases of data extraction. Abbreviations: CINAHL, Cumulative Index to Nursing and Allied Health; ERIC, Education Resources Information Center; TPB, theory of planned behavior. 
Table I Summary of theory of planned behavior-based interventions targeting dietary behaviors in adolescents and young adults ( $\mathrm{n}=\mathrm{I}$ I)

\begin{tabular}{|c|c|c|c|}
\hline$\#$ & Program/priority population & $\begin{array}{l}\text { Theory and } \\
\text { constructs utilized }\end{array}$ & Design/intervention groups \\
\hline $\mathrm{I}$. & $\begin{array}{l}\text { - Anderson et al }{ }^{15} \text { study } \\
\text { - Children (6-7 yo, I0-II yo) }\end{array}$ & $\begin{array}{l}\text { - TPB } \\
\text { - Attitude } \\
\text { - Subjective norm } \\
\text { - Intention }\end{array}$ & $\begin{array}{l}\text { - Cluster RCT } \\
\text { - Tx: School environment and curriculum }(n=69) \\
\text { - Cnt: Passive control }(n=66)\end{array}$ \\
\hline 2. & $\begin{array}{l}\text { - Angelopoulos et } \mathrm{al}^{16} \text { study } \\
\text { - 5th graders (mean age }=10.27 \text { yo) }\end{array}$ & $\begin{array}{l}\text { - TPB } \\
\text { - Attitude } \\
\text { - Subjective norm } \\
\text { - PBC } \\
\text { - Intention }\end{array}$ & $\begin{array}{l}\text { - Cluster RCT } \\
\text { - Tx: Reduce barriers and endorse availability } \\
(n=321) \\
\text { - Cnt: Passive control }(n=325)\end{array}$ \\
\hline 3. & $\begin{array}{l}\text { - Beaulieu and Godin }{ }^{18} \text { study } \\
\text { - Adolescents (12-17 yo) }\end{array}$ & $\begin{array}{l}\text { - TPB } \\
\text { - Attitude } \\
\text { - Subjective norm } \\
\text { - PBC/Self-efficacy } \\
\text { - Intention }\end{array}$ & $\begin{array}{l}\text { - Quasi-experimental, pre-post } \\
\text { - Tx: School and social media campaign }(n=129) \\
\text { - Cnt: Passive control }(n=\mid 12)\end{array}$ \\
\hline
\end{tabular}

4.
- Gratton, Povey, and Clark-Carter ${ }^{19}$ study
- Adolescents (II-I6 yo)

5.
- Let us protect our future

- Jemmott et al ${ }^{20}$ study

- Adolescents (9-16 yo)
- TPB

- Attitude

- Subjective norms

- PBC

- Intention

- TPB

- Attitude

- Intention
- RCT

- Txl: Volitional intervention ( $n=103)$

- Tx2: Motivational intervention $(n=52)$

- Cnt: Active control ( $n=43)$

- Cluster RCT

- Tx: Health promotion $(n=495)$

- Cnt: Active control $(n=562)$

6.

- Karimi-Shahanjarini et al ${ }^{22}$ study

- TPB

- Attitude

- Subjective norms

- PBC

- Intention
- Cluster RCT

- TxI: TPB-only $(n=184)$

- Tx2: TPB plus implementation intention $(n=192)$

- Cnt: Passive control ( $n=225)$ 


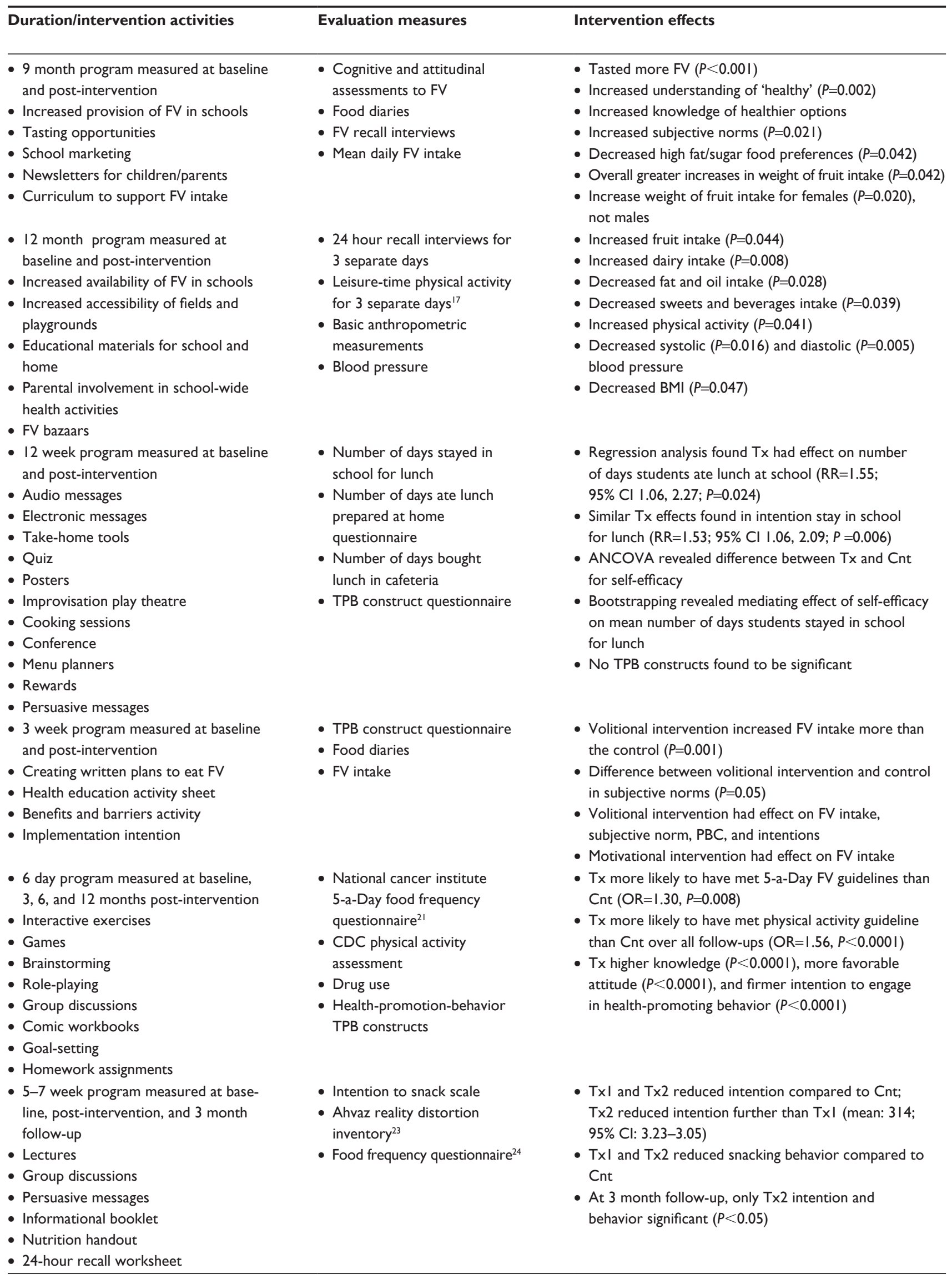


Table I (Continued)

\begin{tabular}{|c|c|c|c|}
\hline \# & Program/priority population & $\begin{array}{l}\text { Theory and } \\
\text { constructs utilized }\end{array}$ & Design/intervention groups \\
\hline 7. & $\begin{array}{l}\text { - Kothe et } \mathrm{al}^{25} \text { study } \\
\text { - First year undergraduate students } \\
\text { (mean age }=19.00 \text { yo) }\end{array}$ & $\begin{array}{l}\text { - TPB } \\
\text { - Attitude } \\
\text { - Subjective norm } \\
\text { - PBC } \\
\text { - Intention }\end{array}$ & $\begin{array}{l}\text { - RCT } \\
\text { - TxI: Positively framed } \\
\text { - Tx2: Negatively framed } \\
\text { - Tx3: PBC } \\
\text { - Cnt: Control }\end{array}$ \\
\hline 8. & $\begin{array}{l}\text { - Fresh facts } 201 \mathrm{I} \\
\text { - Kothe et } \mathrm{a}^{26} \text { study } \\
\text { - First year undergraduate students } \\
\text { (mean age } 18.94 \text { yo) }\end{array}$ & $\begin{array}{l}\text { - TPB } \\
\text { - Attitude } \\
\text { - Subjective norm } \\
\text { - PBC }\end{array}$ & $\begin{array}{l}\text { - Cluster RCT } \\
\text { - TxI: Frequent email }(n=42) \\
\text { - Tx2: Infrequent email }(n=63) \\
\text { - Tx3: Combine treatments from TxI and Tx2 } \\
(n=60)\end{array}$ \\
\hline 9. & $\begin{array}{l}\text { - Prelip et } \mathrm{a}^{27} \text { study } \\
\text { - } 3 \text { rd-5th graders }\end{array}$ & $\begin{array}{l}\text { - TPB } \\
\text { - Attitude } \\
\text { - Behavior }\end{array}$ & $\begin{array}{l}\text { - Cluster RCT } \\
\text { - Tx: Hybrid intervention } \\
\text { - Cnt: Passive control }\end{array}$ \\
\hline 10. & $\begin{array}{l}\text { - Wellness, Academics and You } \\
\text { - Spiegel and Foulk }{ }^{29} \text { study } \\
\text { - Students in 4th and 5th grade classes }\end{array}$ & $\begin{array}{l}\text { - TRA } \\
\text { - Attitude } \\
\text { - Subjective norm }\end{array}$ & $\begin{array}{l}\text { - Quasi-experimental } \\
\text { - Tx: Multidisciplinary intervention }(n=7) \\
\text { - Cnt: Passive control }\end{array}$ \\
\hline II. & $\begin{array}{l}\text { - Tsorbatzoudis }{ }^{31} \text { study } \\
\text { - High school students } \\
\text { (mean age }=\mid 4.8 \text { yo) }\end{array}$ & $\begin{array}{l}\text { - TPB } \\
\text { - Attitude } \\
\text { - Subjective norm } \\
\text { - PBC } \\
\text { - Intention }\end{array}$ & $\begin{array}{l}\text { - Pre-post quantitative design } \\
\text { - Tx: Lectures and posters }(n=\mid 72) \\
\text { - Cnt: Passive control }(n=\mid 63)\end{array}$ \\
\hline
\end{tabular}

Abbreviations: TPB, theory of planned behavior; PBC, perceived behavioral control; Tx, treatment group; Cnt, control or comparison group; $\mathrm{n}$, sample size after attrition; RCT, randomized controlled trial; FV, fruit and vegetable; BMI, body mass index; yo, years old; PA, physical activity; $\mathrm{RR}$, relative risk; $\mathrm{Cl}$, confidence interval; ANCOVA, analysis of covariance; OR, odds ratio; CDC, Centers for Disease Control and Prevention.

in Dundee, Scotland. Schools were matched into pairs based on socioeconomic status and size, then randomly assigned to either treatment (two schools; $\mathrm{n}=511$ subjects) or control (two schools; $\mathrm{n}=464$ subjects) conditions. The intervention consisted of increasing the provision of FV in schools, marketing materials in school cafeterias, newsletters for children and parents, and curriculum materials for teachers. In the treatment schools adolescents $(n=64)$ showed an average increase in fruit consumption ( $133 \pm 1.9$ to $183 \pm 17.0 \mathrm{~g} /$ day $)$ that was greater $(P<0.05)$ than the increase $(100 \pm 11.7$ to $107 \pm 14.2 \mathrm{~g} /$ day) reported in adolescents $(\mathrm{n}=65)$ in control schools. No other changes in food consumption were revealed. Increases in knowledge about FV and subjective norms were also significantly greater in the treatment than in the control group. Researchers concluded that utilizing a whole-school approach to increasing FV consumption has a moderate effect on attitudinal, subjective norms, and fruit consumption.

The study by Angelopoulos et $\mathrm{al}^{16}$ evaluated the outcome of a 12 month intervention that aimed to improve physical activity, dietary behaviors, and anthropometric measures of fifth graders in Ioannina, Greece. Out of 51 primary schools in the area, 26 were randomly chosen to participate as a control or treatment school. Participants $(n=321)$ in the treatment groups were exposed to an increased availability of FV in school, increased accessibility to fields and playgrounds, 


\begin{tabular}{|c|c|c|}
\hline Duration/intervention activities & Evaluation measures & Intervention effects \\
\hline $\begin{array}{l}\text { - I5 minute online program measured at } \\
\text { baseline and I month follow-up } \\
\text { - Persuasive communication tasks } \\
\text { - Implementation intention tasks }\end{array}$ & $\begin{array}{l}\text { - TPB construct assessment } \\
\text { - Breakfast consumption }\end{array}$ & $\begin{array}{l}\text { - No significant between group differences } \\
\text { detected in breakfast consumption }(P>0.05) \\
\text { - From baseline to post-intervention, negatively framed } \\
\text { and control group reported significant increase in } \\
\text { breakfast consumption, but no significant between } \\
\text { group differences } \\
\text { - Baseline PBC and attitude predicted about 39\% of } \\
\text { intention, and baseline intention predicted about 33\% } \\
\text { of behavior at } 4 \text { weeks }\end{array}$ \\
\hline $\begin{array}{l}\text { - } 30 \text { day program measured at baseline } \\
\text { and post-intervention } \\
\text { - Series of emails }\end{array}$ & $\begin{array}{l}\text { - TPB construct assessment } \\
\text { - Amount of FV consumed }\end{array}$ & $\begin{array}{l}\text { - Average of } T \times 1 \text { and } T \times 2 \text { increased FV consumption } \\
\text { from baseline to post-intervention (no } P \text {-value reported) } \\
\text { - No differences in primary and secondary outcomes } \\
\text { between } T \times I \text { and } T x I \\
\text { - Average of } T x I \text { and } T \times 2 \text { increased intention to consume } \\
\text { FV from baseline to post-intervention (no } P \text {-value } \\
\text { reported) }\end{array}$ \\
\hline $\begin{array}{l}\text { - } 9 \text { month program measured at baseline } \\
\text { and post-intervention } \\
\text { - Activities varied by classroom }\end{array}$ & $\begin{array}{l}\text { - Attitudes and beliefs toward FV } \\
\text { - Day in the life questionnaire }{ }^{28}\end{array}$ & $\begin{array}{l}\text { - Change in teacher influence on FV attitude }(P<0.05) \text {. } \\
\text { Negative change for Cnt }(-0.37) \text {; positive change for } \\
\text { TxI }(0.23) \text {. } \\
\text { - Effect in student attitude towards vegetables }(P<0.0 \mathrm{I}) \text {. } \\
\text { Smaller decrease in positive attitude in } \mathrm{TxI}(-0.08) \\
\text { compared to Cnt }(-0.48) \text {. } \\
\text { - No significant increase in FV consumption in } \mathrm{TxI} \text { or Cnt }\end{array}$ \\
\hline $\begin{array}{l}\text { - } 9 \text { month program measured at baseline } \\
\text { and post-intervention } \\
\text { - Understanding of wellness } \\
\text { - Health self-assessment } \\
\text { - Role play } \\
\text { - Journaling } \\
\text { - Nutrition media campaign } \\
\text { - Goal-setting }\end{array}$ & $\begin{array}{l}\text { - Youth Risk Behavior Survey }{ }^{30} \\
\text { - Content knowledge shift } \\
\text { questions }\end{array}$ & $\begin{array}{l}\text { - Significant shift in BMI noted in } \mathrm{Tx} \text { ( } 2 \% \text { reduction in } \\
\text { overweight) } \\
\text { - Increase in FV consumption in Tx and Cnt, with higher } \\
\text { increase in Tx }\end{array}$ \\
\hline $\begin{array}{l}\text { - } 2 \text { week program measured at baseline, } \\
\text { post-intervention and } 2 \text { month follow-up } \\
\text { - Lectures } \\
\text { - Posters } \\
\text { - Persuasive communication discussion } \\
\text { - Goal-setting }\end{array}$ & - TPB construct assessment & $\begin{array}{l}\text { - Higher intentions in } \mathrm{TxI} \text { than in Cnt post-intervention } \\
(F=\mathrm{I} 0.5 \mathrm{I}, \mathrm{P}<0.00 \mathrm{I}) \\
\text { - Higher } \mathrm{PBC} \text { in } \mathrm{T} x \mathrm{I} \text { than in Cnt post-intervention } \\
(F=6.28, P<0.00 \mathrm{I}) \\
\text { - Lower energy intake in } \mathrm{TxI} \text { than in Cnt post- } \\
\text { intervention }(F=5.07, P<0.05)\end{array}$ \\
\hline
\end{tabular}

educational materials for school and home, and various school activities, including FV bazaars where opportunities for FV tasting were offered. Parents were also involved in separate meetings to garner support for the intervention program, and parents were included as planners for various intervention activities at the schools. Participants $(\mathrm{n}=325)$ in control groups did not receive any type of programming. To track nutrition and physical activity behaviors, researchers utilized 24 hour recall interviews and Leisure Time Physical Activity surveys. ${ }^{17}$ Through general mixed modeling and mediating variable analyses, results showed that treatment participants increased fruit $(P=0.044)$ and dairy intake $(P=0.008)$; and decreased fats and oil $(P=0.028)$, and sweets and beverages $(P=0.039)$ intake by the end of the intervention. Vegetable intake was not significantly different post-intervention. Additionally, physical activity increased $(P=0.041)$; while systolic blood pressure ( $P=1.016)$, diastolic blood pressure $(P=1.005)$, and body mass index (BMI) $(P=0.047)$ decreased. Although the intervention was based on preliminary TPB-based questionnaires, TPB constructs were not measured post-intervention.

In the Beaulieu and Godin ${ }^{18}$ article, researchers developed a school-based intervention aimed at discouraging Canadian high school students from eating fast food for lunch by staying at school during the lunch break. In each of the two schools from the same city, with similar socioeconomic statuses, students were randomly selected to participate 
in either the treatment $(n=129)$ or control $(n=112)$. In the treatment school, a 12-week intervention was implemented, which included multiple classroom, lunch time, free period, and parent-directed strategies. Throughout program development and implementation, individuals representative of the target population and stakeholders were consulted. Results showed that the treatment school increased the mean number of days that students remained in school for lunch (relative risk $[\mathrm{RR}]=1.55 ; 95 \%$ confidence interval $[\mathrm{CI}]$ 1.06, 2.27; $P=0.024$ ), as well as the proportion who stayed in school for lunch daily $(\mathrm{RR}=1.21 ; 95 \%$ CI $1.04,1.40 ; P=0.014)$. Self-efficacy was the only psychosocial variable that was influenced by the intervention, probably because of a decline in control group values. The results also indicated that selfefficacy was the only measured construct to show a significant difference between treatment and control groups $(F[1$, 241] $=3.92, P=0.0489$ ).

Gratton et a ${ }^{19}$ developed and evaluated two school-based nutritional programs that aimed to increase FV consumption in adolescents attending secondary schools in Staffordshire, England. Students were randomly allocated to three different groups (one control and two treatment groups) during a 3-week intervention. The volitional intervention group $(n=103)$ was asked to form an implementation intention for where and when they would consume FV, while the motivational intervention group $(n=52)$ completed a health education activity sheet regarding their beliefs about consuming FV daily. The control group $(n=43)$ formed an implementation intention for when and where they would complete homework assignments. Students in all groups recorded a 7-day food diary during the intervention. Results of the study showed that both treatments increased FV consumption; however, only the volitional intervention group demonstrated an increase in $\mathrm{FV}$ consumption over the control group, based on examination of the univariate $F$-values in a MANOVA (multivariate analysis of variance) post hoc analysis $(F[5,140]=14.8, P<0.001)$. Additionally, there was a difference between the volitional intervention group and the control group in subjective norms $(F[5,140]=5.04, P<0.05)$ during post-test. Overall, the treatment that directly addressed intentions had a better outcome of FV consumption.

The study by Jemmott et $\mathrm{al}^{20}$ tested the efficacy of a theory-based program aimed at increasing FV intake and physical activity over 6 consecutive school days in sixth graders attending 35 primary schools in Eastern Cape Province, South Africa. From 17 matched pair schools (and one group of three schools), each school was randomly assigned to either treatment or control group. The treatment $(n=495)$ included activities to make students aware of the relationship between diet and health, to help students assess their individual health habits, and to teach them healthy dietary and physical activity behaviors. Students also received homework about the dietary information they had learned to increase parental involvement as well. The control group $(n=562)$ employed the same amount of sessions, as well as many of the same activities, except with material aimed at increasing safe sex practices, and reducing sexually transmitted diseases. Students in the treatment group were more likely to have met the 5 -a-day ${ }^{21} \mathrm{FV}$ guideline in the past 30 days, compared to participants in the HIV/STD control group, adjusted for baseline response (odds ratio $[\mathrm{OR}]=1.30, P=0.008$ ). The treatment group also showed higher knowledge $(P=0.00001)$, more favorable attitude (mean difference $=0.43, P<0.001$ ) and stronger intention to engage in health-promoting behavior (mean difference $=0.45, P<0.001$ ) when compared to the control group.

The Karimi-Shahanjarini et $\mathrm{al}^{22}$ study developed and implemented a cluster RCT to test the effect of short-term TPB-based treatments on 29 all-female middle school classes in Tehran, Iran. Each class was randomly assigned to TPBbased, TPB plus implementation intention, or control groups. The TPB-based treatment received three sessions conducted 1 to 2 weeks apart: group lecture, a group discussion, and a discussion booklet to keep. The TPB plus implementation intentions group received the three sessions; however, the third session focused around implementation intentions and included a motivational focus group and a booklet with informational and a motivational component. Data on dietary behavior was collected with an intention to snack scale, which the authors developed for this study, and the Food Frequency Questionnaire. ${ }^{23}$ The Ahvez Reality Distortion Inventory ${ }^{24}$ was used to determine social norms. Hierarchical linear modeling revealed that at post-intervention, students in both treatment groups reduced their intention to consume unhealthy snacks more than the control group $(P<0.001)$, and students in the TPB plus implementation intentions group (mean: 2.99; 95\% CI: 3.09-2.89) reported a greater reduction in intention to consume unhealthy snacks than the TBP-only group (mean: 3.14; 95\% CI: 3.23-3.05). Additionally, the TPB-only group $(P<0.01)$ and TPB plus implementation intention group $(P<0.001)$ affected unhealthy snack consumption; there was no statically significant difference between treatment groups. At 3-month follow-up, both treatment groups were still significantly affected by the treatments, although effect sizes were diminished.

Kothe et $\mathrm{al}^{25}$ aimed to increase breakfast consumption in undergraduate college students in Australia by developing and implementing a four-arm randomized control trial. Two 
treatment groups were intended, to change attitudes toward breakfast consumption, one group with a negatively framed message $(n=57)$, and the other with a positively framed message $(n=65)$. The third treatment group focused on PBC framed messages $(n=124)$. All three treatment groups utilized persuasive communication and implementation intentions for increasing breakfast consumption. The fourth group was a passive control group $(n=132)$ that received no programming. Results of a multiple regression showed that baseline attitude, subjective norms, and PBC predicted 39.3\% of baseline intention. Additionally, baseline intention predicted $33 \%$ of breakfast consumption at 1 month. However, none of the treatments resulted in increased breakfast consumption, or any of the TPB antecedents of behavior.

Kothe et $\mathrm{al}^{26}$ developed and assessed the efficacy of a school-based nutritional program, "Fresh Facts 2011", which aimed to increase FV consumption in undergraduate students at a public university in Australia. Students were randomly assigned to two levels of treatment frequency (low $\mathrm{n}=92$, high $\mathrm{n}=102$ ) via email messages. The high frequency group received 27 emails with short messages, and the low frequency group received 9 emails with longer messages over a period of 30 days. At post-test, FV intake increased in both treatment groups (pretest mean=4.2, posttest $\mathrm{M}=5.2$ servings; both groups $P<0$.05). There was also an increase in intention $(P<0.001)$, PBC $(P=0.042)$, attitude $(P<0.001)$, and subjective norm $(P<0.001)$ for both groups. Both TPBbased treatments were successful in changing FV consumption and TPB constructs.

A study by Prelip et $\mathrm{al}^{27}$ assessed the impact of a "hybrid" nutrition education program on TPB constructs and FV consumption for students attending elementary schools in Los Angeles, CA, USA. A total of twelve elementary schools (nine treatment, three control) were randomly assigned to either treatment or control conditions. The treatment conditions consisted of a variety of approaches and teachers were given the freedom to create their own "hybrid" program; teachers were given district-wide resources to utilize, and they could also create their own activities. To assess FV intake, researchers used the Day in the Life Questionnaire, ${ }^{28}$ which has been previously developed and validated. The results of linear mixed modeling indicated that there was no difference in FV consumption from pretest to posttest for both the control and treatment schools. However, student attitudes toward vegetables $(P<0.01)$ and teacher influence on students' attitudes toward FV $(P<0.05)$ significantly improved in the treatment groups.

Spiegel et $\mathrm{al}^{29}$ evaluated the effectiveness of a schoolbased program, "Wellness, Academics and You" (WAY), which aimed to change BMI, FV consumption, and physical activity in fourth and fifth graders from 69 classes in four states in the US. Researchers recruited classes in coordination with local and state education officials. Each participating school included a treatment and a control class, chosen with simple random sampling techniques. The treatment condition $(n=529)$ was based on a TRA framework that engaged students in multidisciplinary activities such as directed-reflective journaling and class discussions that aimed to develop health attitudes, behavioral intent, and behavior. The control group $(n=478)$ did not receive any WAY programming. WAY utilized the Youth Risk Behavior Survey $^{30}$ to measure dietary behaviors. Results revealed an increase in FV consumption in both groups, with a significantly greater increase in the treatment group. Both control and treatment groups increased reported consumption of potatoes and carrots. Lastly, the WAY program changed students' knowledge, attitudes, and behavioral intentions, which led to increased FV intake. WAY also led to changes in BMI status and physical activity levels.

The study by Tsorbatzoudis ${ }^{31}$ tested the effectiveness of a 12-week TPB-based intervention to alter attitudes and healthy dietary behavior of high school students in northern Greece. Three public schools were non-randomly assigned to the treatment group $(n=172)$ and two public schools were non-randomly assigned to the control group $(n=163)$. The treatment condition included posters and lectures promoting healthy eating behaviors. Results of post-test analyses indicated that there were differences between the control and treatment group $\left(F_{1,311}=23.44, P<0.001, d=0.99\right)$ for intention, with the treatment group indicating more positive intentions than the control group. There were also differences for PBC $\left(F_{1,311}=6.28, P<0.001, d=0.70\right)$ between the treatment and control groups. Behavior was measured with total energy intake, which showed a difference between control and treatment groups $\left(\mathrm{F}_{1,311}=9.07, P<0.001, d=0.85\right)$; essentially, the treatment group reported less energy consumption than the control.

\section{Discussion}

The major aim of this investigation was to systematically review and synthesize TPB and TRA-based dietary behavior interventions directed at adolescents and young adults. Adolescent and young adult dietary behaviors are clearly a global concern as the studies in this review were from many parts of the world: three in North America, two in Australia, one in the Middle East, one in South Africa, and four in Europe. Although there have been many studies examining the ability of TPB and TRA to predict various dietary behav- 
iors, very few articles have assessed a TPB or TRA-based intervention that aimed to change dietary behaviors, and even fewer have directed these interventions at adolescents or young adults. To determine best practices for theory-based dietary interventions for this priority population, there is a tremendous need to develop, implement, and evaluate similar programs derived from recent literature. A summary of each intervention is provided in Table 2 .

The findings from this systematic analysis suggest effectiveness of TPB and TRA-based dietary interventions in the priority population is modest. Of the eleven intervention studies evaluated, nine resulted in dietary behavior change that was attributed to the treatment. Additionally, all but one study found there to be a change in at least one measured construct, while one study did not measure changes in TPB or TRA constructs post-intervention. However, the majority of the studies $(n=7)$ did not incorporate any type of follow-up measures to determine if there were lasting effects of the interventions. Without any substantial follow-up measurements, researchers can only assess immediate and short-term changes without determining any long-term changes in behavioral antecedents or behavior.

\section{Intervention design Strengths}

All of the studies utilized some type of quantitative design, with one employing pre-post, two employing quasi-experimental, and seven employing RCT designs.
RCT designs are preferred over other quantitative designs, and are typically considered the gold standard of research designs because they help control for common threats to both internal and external validity. Of those that were RCTs, five were cluster RCTs, which allows for schoolbased programs to assign entire classrooms or schools to one condition. Although cluster RCTs can be vulnerable to a wide range of biases, ${ }^{32}$ this study design is commonly applied in school-based programming in order to avoid contamination between groups or individuals assigned to different conditions.

Cultural tailoring, intentionally adapting interventions in order to make them more appropriate to ethnic or racial priority populations, ${ }^{33}$ is essential to the success of intervention programming in many priority populations. Kreuter et $\mathrm{al}^{34}$ state that in order to create culturally sensitive programs, "health educators must be able to identify and describe cultures and/or subcultures within a given population, understand how each relates to health behavior, and apply this knowledge in planning and development activities". Within the reviewed articles, two were presented with the challenge of cultural tailoring. In both studies, researchers entered a minority, low socioeconomic status community, built relationships, and developed the intervention based off the needs, resources, and assets of the community. Often, there is a lack of research done with ethnic or racial minority populations, which generally present the greatest need for health programming. Future interventions should focus on minority

Table 2 Summary of articles

\begin{tabular}{|c|c|c|c|c|c|c|c|}
\hline Author & Year & Country & $\begin{array}{l}\text { Dietary outcome } \\
\text { behavior }\end{array}$ & $\begin{array}{l}\text { Persuasive } \\
\text { messages }\end{array}$ & $\begin{array}{l}\text { Implementation } \\
\text { intention }\end{array}$ & $\begin{array}{l}\text { Intervention } \\
\text { duration }\end{array}$ & $\begin{array}{l}\text { Significant change } \\
\text { in behavior }\end{array}$ \\
\hline Anderson et al $^{15}$ & 2005 & Scotland & FV intake & & & 9 months & $x$ \\
\hline Angelopoulos et $\mathrm{al}^{16}$ & 2009 & Greece & $\begin{array}{l}\text { Several dietary } \\
\text { behaviors }\end{array}$ & & & 12 months & $x$ \\
\hline Beaulieu and Godin ${ }^{18}$ & 2012 & Canada & $\begin{array}{l}\text { Stay in school for } \\
\text { lunch }\end{array}$ & $X$ & & 12 weeks & $x$ \\
\hline $\begin{array}{l}\text { Gratton, Povey and } \\
\text { Clark-Carter }^{19}\end{array}$ & 2007 & England & FV intake & & $x$ & 3 weeks & $x$ \\
\hline Jemmott et $\mathrm{al}^{20}$ & 2011 & South Africa & FV intake & & & 6 days & $x$ \\
\hline $\begin{array}{l}\text { Karimi-Shahanjarini } \\
\text { et } \mathrm{al}^{22}\end{array}$ & 2013 & Iran & $\begin{array}{l}\text { Unhealthy snack } \\
\text { consumption }\end{array}$ & $X$ & $x$ & 3 months & $x$ \\
\hline $\begin{array}{l}\text { Kothe, Mullan and } \\
\text { Amaratunga }^{25}\end{array}$ & 2011 & Australia & $\begin{array}{l}\text { Breakfast } \\
\text { consumption }\end{array}$ & $X$ & $x$ & 15 minutes & \\
\hline $\begin{array}{l}\text { Kothe, Mullen and } \\
\text { Butow }^{26}\end{array}$ & 2012 & Australia & FV intake & & & 30 days & $x$ \\
\hline Prelip et $\mathrm{al}^{27}$ & 2011 & USA & FV intake & & & 9 months & \\
\hline Spiegel and Foulk ${ }^{29}$ & 2006 & USA & FV intake & & & 9 months & $x$ \\
\hline Tzorbatzoudis $^{31}$ & 2005 & Greece & $\begin{array}{l}\text { Healthy eating } \\
\text { habits }\end{array}$ & $\mathrm{X}$ & & 12 weeks & $x$ \\
\hline
\end{tabular}

Note: The designation of ' $X$ ' represents the presence of the attribute in the design of the intervention. Abbreviation: FV, fruit and vegetable. 
communities to determine the best approaches for addressing culturally sensitive dietary behavior interventions.

Implementation intention, which is a concept that identifies the process of translating intention into behavior, was utilized in three studies. Although implementation intention is not an original component of TPB, it has been successfully utilized in dietary behavior change programs. ${ }^{35}$ Additionally, TPB and TRA research indicates that intention directly predicts behavior, which provides a substantial motivation to include implementation intention in future studies. Researchers use implementation intention as an extension of TPB or TRA to further close the gap between intention and behavior. ${ }^{12}$ Interventions in this review enacted implementation intention by asking participants to specify how, where, and when they would perform a dietary behavior change and to try to put their behavior plans into action.

\section{Limitations}

Although each program utilized either TPB or TRA, only a few of them operationalized each measured construct. Latent variables theorized to mediate behavior are unobservable by nature, and must be quantified through a process of instrumentation. Once quantified, the variables must be assessed for validity and reliability using accepted psychometric standards. Without proper operationalization and measurement of theoretical constructs, it can be difficult for researchers to determine if the intervention reified the given theoretical framework correctly. By defining each construct and explaining how each construct will be measured before program implementation, researchers can determine the effects of each variable on behavior. Additionally, by operationalizing each variable, researchers can more easily replicate study procedures.

A major advantage of using theory as a framework for interventions is the ability to determine how well the antecedents actually predicted behavioral intention and behavior. Although all of the reviewed studies used TPB or TRA, only two studies evaluated the predictive power of antecedents on dietary behavior. Understanding the strength of influence that each antecedent had on behavior can help researchers determine how successful their design was, compare to similar research using the same antecedents, and inform future research.

\section{Intervention implementation Strengths}

There was a wide range of durations applied in the reviewed interventions; programs ranged from 15 minutes to 9 months. The majority $(\mathrm{n}=10)$ of the studies implemented treatments over several sessions. Half $(n=6)$ of the interventions lasted between 3 and 12 months. Since developing healthy dietary behaviors is a complex process that is influenced by many factors, it is likely that continuous programming over a long period is needed. The vast majority of the studies incorporated multiple sessions over a long period of time to allow the antecedents of and behavior to change. Additionally, very brief interventions may not go into appropriate depth about the behavior change or utilize effective activities, which may not be sufficient to change the antecedents of behavior or actual behavior. To determine intervention efficacy, future interventions should include longer treatment periods.

Among the reviewed studies, several $(n=4)$ had participants utilize technology as part of the intervention components. These components included emails, social media posts, information on school websites, web-based activities, audio messages in classrooms, interactive DVDs, and health-related websites. According to Subrahmanyam and Lin, ${ }^{36}$ adolescents are the fastest growing and largest demographic to utilize the Internet for an increasing number of social, personal, and academic pursuits. Incorporating mediabased components that are commonly used by this age-group may be beneficial to overall program success. However, in some circumstances, technology may be either unfeasible or inappropriate, such as in a low socioeconomic setting.

All of the reviewed studies $(n=11)$ utilized multiple strategies, or modalities of changing behavior. The Institute of Medicine recommends that multiple strategies be employed in adolescents when trying to change health behaviors such as dietary behavior. ${ }^{37}$ Utilizing different strategies, although usually requiring more planning and resources, could improve the overall effectiveness of interventions. One single strategy will most likely not be effective with an entire sample population, and therefore it is wise to approach antecedents and behavior in different ways.

A minority of the studies $(n=4)$ incorporated physical activity (PA) into their activities and evaluation. If the major aim of the study is to reduce obesity and related health outcomes, implementing PA strategies and measuring PA along with improving dietary behavior may yield better outcomes in anthropometric measures. There is conflicting evidence about the efficacy of diet only versus diet and PA interventions. ${ }^{38}$ Combined diet and PA programs have been successful in adult populations and have a promising future for adolescent obesity reduction and prevention research.

Of the articles reviewed, two included goal setting as a strategy. As a dietary intervention strategy, goal setting has been growing in popularity. In conjunction with other com- 
ponents that are designed to motivate, goal setting may help bridge the gap between intention and behavior. Strecher et a ${ }^{39}$ suggest that because dietary behaviors are often complex, goal setting should be used for simple dietary changes (eg, exchanging sugar-sweetened beverages for water), rather than complex, more involved dietary changes (eg, reducing saturated fat intake by $15 \%$ ). Many of the reviewed studies focused on straightforward, simple outcomes, such as FV intake and unhealthy snacking. Although performing dietary change such as FV intake can be difficult, incorporating other components such as increasing the provision of $\mathrm{FV}$ in schools and creating tasting opportunities can remove barriers to FV intake and bolster goal setting.

Persuasive communication was utilized in four of the studies included in this review. According to Hardeman et al, ${ }^{13}$ interventions that use persuasive messages are more likely to result in behavior change. Persuasive communication was suggested by Ajzen and Fishbein ${ }^{11}$ as the method to change beliefs, and other research ${ }^{40}$ has demonstrated that persuasive messages targeting relevant beliefs can influence intention, which directly influences behavior. Including persuasive communication in conjunction with other intervention components should be considered when developing future related research.

\section{Limitations}

Only three of the reviewed studies incorporated multiple settings into their intervention implementation. Taking an ecological approach by expanding interventions to multiple settings can help adolescents and young adults integrate what they may have learned in a school-based program and apply it to a home or community setting. Interventions that are only focused in one setting fail to recognize and address other major settings in which the behavior will be performed. The interventions that utilized more than one setting were primarily based in the school, with additional home-based components. Although these components were simple (ie, newsletters for families, homework for children and parents to complete together), they addressed other important settings in regard to eating habits.

\section{Evaluation design Strengths}

Although it is optimal to utilize a standardized, widely accepted measurement tool, it is not often feasible to do so. Of the reviewed studies, five employed widely used measurement tools for a major outcome measure. For FV intake, the 5-a-Day Food Frequency Questionnaire ${ }^{21}$ is commonly used to determine whether individuals meet the 5-a-Day FV recommendation. Another standardized measurement tool, the Youth Risk Behavior Survey, ${ }^{30}$ first developed by the Centers for Disease Control, tracks dietary behaviors, among others. These and other standardized measurement tools have been used regularly by researchers and can be more easily compared because of their wide use.

\section{Limitations}

Only two of the studies included an objective anthropometric outcome variable. It is difficult to objectively measure certain behaviors, such as dietary behavior. Instead, investigators have determined how to measure this through self-report or proxy report. The two studies measuring long-term changes in BMI enabled researchers to objectively measure height and weight at each time point to compare any changes in BMI. Although dietary behaviors do not directly determine BMI, measures of weight status and obesity indirectly relate to dietary behaviors, and should be utilized in long-term outcome measures of the effectiveness of dietary behavior interventions. There is an incredible need to develop objective measures that directly assess dietary behaviors.

None of the reviewed studies included process evaluation within their interventions. Process evaluation refers to measuring whether each program activity is delivered as intended, and is an important part of any intervention because it can help determine program fidelity. Programs with high fidelity can rule out poorly implemented program components as a reason for any non-significant findings. Future intervention studies should use process evaluation in order to help determine efficacy of program components.

\section{Practical implications and recommendations}

Interventions directed toward changing dietary behaviors in adolescents should aim to incorporate multi-faceted, theorybased approaches. Incorporating theoretical frameworks into dietary behavior interventions will help guide researchers to better evaluate the effectiveness of their interventions, since they are able to measure antecedents of behavior. Other theoretical frameworks should be employed to determine the utility of different theories on changing dietary behavior. Social cognitive theory ${ }^{41}$ has been used as a framework in which to develop interventions directed at eating behaviors. The construct of self-regulation has been shown to be effective through goal-setting within healthy eating interventions. ${ }^{42,43}$ The social ecological model ${ }^{44}$ incorporates five layers of influence on behavior including individual, interpersonal, institutional, community, and policy. Because dietary 
behavior change is a complex behavior influenced by many factors, creating multi-layered interventions may be a more appropriate approach. Changing the school environment, reducing the cost of FV and other healthy foods, influencing significant-others, and focusing on the individual may not be feasible in every situation, but it could have a robust and lasting impact on dietary behavior.

Future studies should consider utilizing RCTs, or a variation of RCTs (ie, cluster RCTs) in order to maintain a high amount of rigor and quality. Although quasi-experimental studies may be more feasible in some situations, randomization is essential to ensuring equality between groups. Cluster RCTs could ease some of the burden of lacking the ability to randomly assign individuals. The school setting is where many dietary behavior interventions for adolescents and young adults take place, creating an environment that is suitable for a cluster RCT. However, if a cluster RCT design is used, mixed models should be considered in order to measure the effect of the group (cluster) or potential loss of independence that may exist in the individual. ${ }^{45}$ Overall, the quality of the studies was quite high, since RCT was used the majority of the time. The other studies, however, lacked either randomization, or a control group. Additionally, one cluster RCT developed an intervention that varied by classroom. Keeping better records of each classroom's activities, as well as including process evaluation, may have been helpful, especially in this case, to determine the efficacy of specific programs within the intervention.

\section{Conclusion}

There is a clear need to improve dietary behaviors in adolescents and young adults worldwide. By developing and implementing multi-component, theory-based RCTs, which include rigorous (process, impact, and outcome) evaluations, researchers can determine the mediators of behavior and modify them to change dietary behaviors. The overall impact of theory-based, multi-component interventions can be the reduction of obesity and other related health issues that will allow people to live longer, healthier lives.

\section{Disclosure}

The authors have no conflicts of interest to disclose in this work.

\section{References}

1. WHO. Obesity: preventing and managing the global epidemic. World Health Organization Technical Report Series 894. 2000. Available from http://www.who.int/nutrition/publications/obesity/WHO_TRS_894/en/. Accessed March 12, 2014.
2. Pi-Sunyer FX. Medical hazards of obesity. Ann Intern Med. 1993; 119(7/2):655-660.

3. Deckelbaum RJ, Williams CL. Childhood obesity: the health issue. Obes Res. 2001;9(S11):239S-243S.

4. Whitaker RC, Wright JA, Pepe MS, Seidel KD, Dietz WH. Predicting obesity in young adulthood from childhood and parental obesity. N Engl J Med. 1997;337(13):869-873.

5. Ogden CL, Carroll MD, Kit BK, Flegal KM. Prevalence of obesity and trends in body mass index among US children and adolescents, 1999-2010. JAMA. 2012;307(5):483-490.

6. Hall KD, Heymsfield SB, Kemnitz JW, Klein S, Schoeller DA, Speakman JR. Energy balance and its components: implications for body weight regulation. Am J Clin Nutr. 2012;95(4):989-994.

7. Daniels SR, Arnett DK, Eckel RH, et al. Overweight in children and adolescents: pathophysiology, consequences, prevention, and treatment. Circulation. 2005;111(15):1999-2012.

8. Epstein LH, Gordy CC, Raynor HA, Beddome M, Kilanowski CK, Paluch R. Increasing fruit and vegetable intake and decreasing fat and sugar intake in families at risk for childhood obesity. Obes Res. 2001;9(3):171-078.

9. Poddar K, Hosig K, Anderson E, Nickols-Richardson S, Duncan S. Webbased nutrition education intervention improves self-efficacy and selfregulation related to increased dairy intake in college students. Journal Of The American Dietetic Association [serial online]. November 1, 2010;110(11):1723-1727.

10. Ajzen I. The theory of planned behavior. Organizational Behavior and Human Decision Processes. 1991;50(2):179-211.

11. Ajzen I, Fishbein M. Understanding Attitudes and Predicting Social Behavior. Englewood Cliffs, NJ: Prentice-Hall, 1980.

12. Armitage CJ, Conner M. Efficacy of the theory of planned behaviour: A meta analytic review. Brit J Soc Psychol. 2001;40(4):471-499.

13. Hardeman W, Johnston M, Johnston D, Bonetti D, Wareham N, Kinmonth AL. Application of the theory of planned behaviour in behaviour change interventions: a systematic review. Psychology and Health. 2002;17(2):123-158.

14. Munoz KA, Krebs-Smith SM, Ballard-Barbash R, Cleveland LE. Food intakes of US children and adolescents compared with recommendations. Pediatrics. 1997;100(3):323-329.

15. Anderson AS, Porteous LEG, Foster E, et al. The impact of a schoolbased nutrition education intervention on dietary intake and cognitive and attitudinal variables relating to fruits and vegetables. Public Health Nutr. 2005;8(6):650-656.

16. Angelopoulos P, Milionis H, Grammatikaki E, Moschonis G, Manios Y. Changes in BMI and blood pressure after a school based intervention: The CHILDREN study. Eur J Public Health [serial online]. June 1, 2009;19(3):319-325.

17. Manios Y, Kafatos A, Markakis G. Physical activity of 6-year-old children: Validation of two proxy reports. Pediatr Exerc Sci. 1998; 10(2):176-188.

18. Beaulieu D, Godin G. Staying in school for lunch instead of eating in fast-food restaurants: results of a quasi-experimental study among high-school students. Public Health Nutr. 2012;15(12):2310.

19. Gratton L, Povey, R, Clark Carter D. Promoting children's fruit and vegetable consumption: interventions using the Theory of Planned Behaviour as a framework. Brit J Health Psych. 2007;12(4): 639-650.

20. Jemmott JB III, Jemmott LS, O’Leary A, et al. Cognitive-behavioural health-promotion intervention increases fruit and vegetable consumption and physical activity among South African adolescents: a cluster-randomised controlled trial. Psychology and Health. 2011;26(2):167-185.

21. Thompson F, Byers T, Kohlmeier L. Dietary assessment resource manual. J Nutr. 1994;124:2305S-2306S.

22. Karimi-Shahanjarini A, Rashidian A, Omidvar N, Majdzadeh R. Assessing and comparing the short-term effects of TPB only and TPB plus implementation intentions interventions on snacking behavior in Iranian adolescent girls: a cluster randomized trial. Am J Health Promot, 2013;27(3):152-161.

23. Najarian B, Soudani M. Construction and validation of a scale for the measurement of reality distortion. Educ Psychol. 2001;8:99-114. 
24. Minniran P, Azadbakht L, Azizi F. Dietary behavior of Tehranian adolescents does not accord with their nutritional knowledge. Public Health Nutr. 2007;10:897-901.

25. Kothe EJ, Mullan BA, Amaratunga R. Randomised controlled trial of a brief theory-based intervention promoting breakfast consumption. Appetite. 2011;56(1):148-155.

26. Kothe EJ, Mullan BA, Butow P. Promoting fruit and vegetable consumption. Testing an intervention based on the theory of planned behaviour. Appetite. 2012;58(3):997-1004.

27. Prelip M, Slusser W, Thai CL, Kinsler J, Erausquin JT. Effects of a school based nutrition program diffused throughout a large urban community on attitudes, beliefs, and behaviors related to fruit and vegetable consumption. J School Health. 2011;81(9):520-529.

28. Edmunds LD, Ziebland S. Development and validation of the Day in the Life Questionnaire (DILQ) as a measure of fruit and vegetable questionnaire for 7-9 year olds. Health Educ Res. 2002;17(2): 211-220.

29. Spiegel SA, Foulk D. Reducing overweight through a multidisciplinary school based intervention. Obesity. 2006;14(1):88-96.

30. Centers for Disease Control and Prevention. [survey year] Youth Risk Behavior Survey. Available at: www.cdc.gov/yrbs. Accessed on October 12, 2013.

31. Tzorbatzoudis H. Evaluation of a planned behavior-based intervention programme to promote healthy eating. Percept Motor Skill. 2005;101: 587-604.

32. Puffer S, Torgerson DJ, Watson J. Cluster randomized controlled trials. J Eval Clin Pract. 2005;11(5):479-483.

33. Botvin GJ. Advancing prevention science and practice: Challenges, critical issues, and future directions. Prevention Science. 2004;5(1): 69-72.

34. Kreuter MW, Lukwago SN, Bucholtz DC, Clark EM, SandersThompson V. Achieving cultural appropriateness in health promotion programs: targeted and tailored approaches. Health Educ Behav. 2003;30(2):133-146.
35. Sheeran P, Webb TL, Gollwitzer PM. The interplay between goal intentions and implementation intentions. Pers Soc Psychol B. 2005;31: 87-98.

36. Subrahmanyam K, Lin G. Adolescents on the net: Internet use and well-being. Adolescence. 2007;42(168):659-677.

37. Koplan J, Liverman C, Kraak V, editors. Preventing Childhood Obesity: Health in the Balance. Washington, DC: National Academies Press; 2005.

38. Doak CM, Visscher TLS, Renders CM, Seidell JC. The prevention of overweight and obesity in children and adolescents: a review of interventions and programmes. Obesity Reviews. 2006;7(1): 111-136.

39. Strecher V, Seijts G, Kok G, et al. Goal setting as a strategy for behavior change. Health Education Quarterly. 1995;22:190-220.

40. Chatzisarantis NLD, Hagger MS. Effects of a brief intervention based on the Theory of Planned Behavior on leisure time physical activity participation. J Sport Exerc Psychol. 2005;27:470-487.

41. Bandura A. Social Foundations Of Thought and Action: A social cognitive theory. 1986. Englewood Cliffs, NJ, USA: Prentice-Hall.

42. Pelletier LG, Dion SC, Slovinec-D'Angleo M, Reid R. Why do you regulate what you eat? Relationships between forms of regulation, eating behaviors, sustained dietary behavior change, and psychological adjustment. Motiv Emotion. 2004;28:245-277.

43. Anderson ES, Winett RA, Wojcik J R. Self-regulation, self-efficacy, outcome expectations, and social support: social cognitive theory and nutrition behavior. Ann Behav Med. 2005;34(3):304-312.

44. Bronfenbrenner U. Toward an experimental ecology of human development. Am Psychol. 1977;32(7):513. Available from: http:// maft.dept.uncg.edu/hdf/facultystaff/Tudge/Bronfenbrenner\%201977. pdf. Accessed April 10, 2014.

45. Raudenbush S, Bryk A. Hierarchical Linear Models. 2nd ed. New York: Sage, 2002.
Adolescent Health, Medicine and Therapeutics

\section{Publish your work in this journal}

Adolescent Health, Medicine and Therapeutics is an international, peer-reviewed, open access journal focusing on health, pathology, and treatment issues specific to the adolescent age group. All aspects of health maintenance, preventative measures and disease treatment interventions are addressed within the journal and practitioners from

\section{Dovepress}

all disciplines are invited to submit their work as well as healthcare researchers and patient support groups.. The manuscript management system is completely online and includes a very quick and fair peerreview system. Visit http://www.dovepress.com/testimonials.php to read real quotes from published authors. 